Keywords: Borderline Personality Disorder; Nightmares; Affect regulation; Fantasy.

\title{
Nightmares and bad dreams in patients with borderline personality disorder: Fantasy as a coping skill?
}

\section{Peter Simor ${ }^{*, *}$ \\ Szilvia Csóka ${ }^{\star * *}$ Róbert Bódizs ${ }^{\star \star *, * * \star *}$}

* Implicit Laboratory Association, Budapest

** Department of Cognitive Sciences, Budapest University of Technology and Economics, Budapest

*** Institute of Behavioural Sciences, Semmelweis University, Budapest

${ }^{* * * *}$ HAS-BME Cognitive Science Research Group, Hungarian Academy of Sciences, Budapest

HUNGARY

\footnotetext{
ABSTRACT - Background and Objectives: Previous studies reported a high prevalence of nightmares and dream anxiety in Borderline Personality Disorder (BPD) and the severity of dream disturbances correlated with daytime symptoms of psychopathology. However, the majority of these results are based on retrospective questionnaire-based study designs, and hence the effect of recall biases (characteristic for BPD), could not be controlled. Therefore our aim was to replicate these findings using dream logs. Moreover, we aimed to examine the level of dream disturbances in connection with measures of emotional instability, and to explore the protective factors against dream disturbances.

Methods: 23 subjects diagnosed with BPD, and 23 age and gender matched healthy controls were assessed using the Dream Quality Questionnaire, the Van Dream Anxiety Scale, as well as the Neuroticism, Assertiveness and Fantasy scales of the NEO-PI-R questionnaire. Additionally, subjects were asked to collect 5 dreams in the three-week study period and to rate the emotional and phenomenological qualities of the reported dreams using the categories of the Dream Quality Questionnaire.

Results: Dream disturbances (nightmares, bad dreams, night terror-like symptoms, and dream anxiety) were more frequent in patients with BPD than in controls. Dream disturbances correlated positively with Neuroticism, while Fantasy proved to be a negative correlate of dream disturbances.
} 
Conclusions: Our study provides further support for the association between dream disturbances and BPD, links the presence of dream disturbances to the levels of emotional instability, and suggests that fantasy is a potential protective factor against dysfunctional dreaming.

Received: 8 April 2009

Revised: 8 October 2009

Accepted: 20 October 2009

\section{Introduction}

Sleep disorders are frequent, but relatively less emphasized in the diagnosis of Borderline Personality Disorder (BPD). However, patients diagnosed with BPD spend more time in REM sleep than healthy controls $^{1}$, their sleep is characterized by shorter REM latency, and increased REM density especially in the first REM cycle ${ }^{2}$, they report worse sleep quality than controls, and show depression-like sleep disturbances ${ }^{3}$. Frequent nightmares and dream anxiety disrupting sleep and waking functioning are also reported in BPD, and disturbed sleep quality reflects the severity of psychopathological symptoms, dissociative experiences and childhood trauma found in patients with $\mathrm{BPD}^{4,5}$. Moreover, dissociative symptoms and suicidal behaviour (characteristic for BPD) are associated with recurrent nightmares in different populations ${ }^{6-9}$. Nightmares disrupting sleep may deepen dissociative symptoms, since sleep loss elicits dissociative symptoms even in healthy volunteers according to a prospective study ${ }^{10}$. Except this study, the majority of the investigations were based on retrospective study designs, using sleep-questionnaires. As patients with BPD are highly susceptible to recall biases, it should be clarified if dream disturbances can be observed in a study de- sign that examines the emotional characteristics of specific dream reports. Therefore our aim was to replicate the findings showing disturbed dreaming in BPD, and to clarify if the negative emotional aspects of dreaming are present in the specific dream reports as well. Collecting dream reports can also be viewed as a retrospective method, since it is based on memory processes, however specific dream reports in form of dream diaries are less susceptible to recall biases. Cippoli and Poli ${ }^{11}$ demonstrated that the story-like organization of dreams does not differ between laboratory awakenings and morning reports. This suggests that dream logs are valuable and authentic tools to examine the dream quality of the individuals ${ }^{11}$. Since nightmares are linked to a personality disposition characterized by emotional reactivity and vulnerability ${ }^{12}$ we wanted to examine the level of dream disturbances in connection with the severity of emotional instability. Finally, we aimed to explore the protective factors against dream disturbances. Waking Fantasy and Assertiveness were focuses of our study, because the former had been related to the phenomenological qualities of dreaming ${ }^{13}$, and to an ability to integrate the random dream images into a coherent plot $^{14}$, while the latter is thought to be an important coping skill in stress-full life situations, and its development is crucial in the therapy of BPD patients ${ }^{15}$. 


\section{Methods}

\section{Participants}

23 patients (19 female and 4 male) meeting the DSM-IV diagnostic criteria of BPD and 23 age- and gender-matched healthy volunteers participated in the study. The diagnosis of BPD was confirmed by experienced clinicians, using the Hungarian version of the SCID-II ${ }^{16}$. Previous findings indicated that the Hungarian version of the SCID-II is characterized by excellent inter-rater reliability, and construct validity ${ }^{16}$. Subjects with other Axis II co-diagnoses were not included and patients with PTSD and Substance Abuse could not enter the study. The former because of the confounding factor of post-traumatic nightmares, the latter because of the influence that drugs and alcohol exert on sleep architecture $^{17}$. 6 of the 23 BPD subjects were on their regular antidepressant (SSRI) medication during the study. The BPD patients were recruited from Hungarian psychiatric institutes and outpatient clinics. Written informed consent was obtained from the subjects, and the Local Ethics Committee approved the study protocol.

\section{Procedure}

Participants were told that the purpose of the study was to investigate their sleeping and dreaming habits, and the relationship between dreaming and personality. Subjects were asked to fill in the Van Dream Anxiety Scale $^{18}$, the Dream Quality Questionnaire ${ }^{19}$, as well as the Neuroticism, the Assertiveness and the Fantasy scales of the Hungarian version of the NEO-PI- $R^{20}$. After completing the questionnaires subjects were asked to keep a dream diary, recording 5 "home dreams" within the three-week period of the study. The subjects had to write down the collected dreams in the morning after awakening, on a sheet of paper, and on the basis of the shortened version of the Dream Quality Questionnaire - they had to rate the emotional load, the bizarreness, the vividness and the effect on waking mood of each reported dream.

\section{Instruments}

The Van Dream Anxiety Scale (VDAS) provides the assessment of nightmare frequency and dream anxiety caused by frightening dreams. The items of the self-rating scale are concerned with nightmare frequency and the maleficent effects of nightmares on daytime functioning Items are weighted on a 0-4 scale and summed to yield a global VDAS score of 0-42. According to our results based on a sample of 70 patients diagnosed with adaptation disorder and 70 matched controls, the VDAS has been shown to be a valid and reliable instrument to measure nightmare frequency and dream anxiety (Cronbach's a $=0.96$ ). All items are loading on one factor explaining $73 \%$ of the intersubject variance.

The Dream Quality Questionnaire (DQQ) containing 11 dream-specific items, measures the clinically relevant aspects of dreaming, like the emotional load, the bizarreness, and the vividness of dreams, the tendency of experiencing frequent non-recurrent and recurrent nightmares and night-terror-like symptoms, and the effects of dreams on daytime mood. The $D Q Q$ contains three main factors, the positive, the negative and the neutral emotional aspects of habitual dreaming. According to our results based on the data of a large national sample consisting of 5009 individuals, the negative emotional aspects of dreaming was inversely related to the levels of well-being, while the 
positive emotional aspects of dreaming was positively associated with well-being. To sum up DQQ proved to be a valid and reliable psychometric instrument assessing the emotional quality of dreaming ${ }^{19}$.

The shortened version of the DQQ was used to measure the quality of the reported dreams. The 4 items measured the emotional load, the bizarreness, the vividness and the effect on waking mood of each reported dream. The emotional load of the reported dream was asked to be rated by a 5 -point scale $(0$ - expressly oppressive, 1 - bad, 2 - neutral, 3 happy, 4 - expressly gratifying). The average of the ratings generated the DE (Dream Emotion) score. The effect of the reported dream on daytime mood was also measured by a 5point scale. The average of the ratings generated the DI (Dream Influence) score.

The NEO-PIR-H1 was used to measure the emotional instability of the subjects. The Neuroticism factor contains the following subscales: Anxiety, Anger and Hostility, Depression, Self-Consciousness, Impulsivity and Vulnerability. The internal consistency of the Neuroticism Factor as measured by the Cronbach's $\alpha$ was 0.92 . The Cronbach's $\alpha$ coefficients for the Assertiveness and Fantasy scales were 0.77 and 0.81 respectively. The validity of the NEO-PIR-H1 was tested with the FFPI$\mathrm{H}$, the Five Factor Personality Inventory (Hungarian version $)^{20}$. The correlation of the Neuroticism factor with the Emotional Stability factor of the FFPI-H was $-0.54(p<0.05)$.

\section{Results}

One subject from the BPD group failed to report any dream in the study period, therefore his results were excluded from the analysis of prospective, but not retrospec- tive dream data. This way we examined the results of the completed questionnaires, and the ratings of a total of 209 dream reports. Some of the subjects ( 3 from the BPD and 4 from the control groups) provided less than 5 dreams. The mean frequency of reported dreams was 4.64 per subject $(\mathrm{SD}=1.09)$. Groups did not differ in their reported dream frequency $(\mathrm{t}=-0.04 ; \mathrm{p}=0.96)$.

\section{Habitual dream behaviour: retrospective results}

The two groups differed significantly in several variables of the Dream Quality Questionnaire. 50\% (SD = 0.51) of the BPD group reported frequent nightmares that caused sudden awakenings, but only $9 \%$ $(\mathrm{SD}=0.29)$ of the control group reported the same experience. This difference was significant according to the Fisher exact probe $(\mathrm{p}=0.0027)$. Similarly $68.1 \%$ (SD = 0.46 ) of the BPD group reported night terror-like symptoms as compared to the $22 \%$ $(\mathrm{SD}=0.42)$ of the controls that according to the Fisher exact probe proved to be significant $(p=0.002)$. Furthermore, the BPD group suffers more frequently from recurrent nightmares than the healthy control group [(Mean: $2.55(\mathrm{SD}=1.05)$ vs. $1(\mathrm{SD}=1)] ; \mathrm{t}=5.03 ; \mathrm{p}<$ 0.001). BPD and control subjects differed significantly on the three DQQ factors. BPD patients achieved significantly higher scores on the negative emotional aspects of dreaming factor [Mean (BPD): $8.12(\mathrm{SD}=3.28)$; Mean (control): 3.63 (SD = 1.99)]; $(\mathrm{F}=23.45$; df $=1,44 ; \mathrm{p}=0.000019$ ), while the control group achieved higher scores in the factors of positive [Mean (BPD): $1.70(\mathrm{SD}=0.94)$; Mean (control): $2.36(\mathrm{SD}=0.78)]$ and neutral aspects of dreaming [Mean (BPD): 1.44 $(\mathrm{SD}=0.79)$; Mean (control): 2.05 ( $\mathrm{SD}=$ $0.83)] ;(\mathrm{F}=6.81 ; \mathrm{df}=1,44 ; \mathrm{p}=0.0124$ and $\mathrm{F}$ $=5.52 ; \mathrm{df}=1,44 ; \mathrm{p}=0.0235$ respectively . 
Independent sample t-tests were used to compare the means of the VDAS scores of the BPD and the control group. The mean value of the BPD group was 23.55 (SD = 15.46) while for the control group it was 5.04 ( $\mathrm{SD}=5.44)$. The difference was significant $(\mathrm{t}=5.31 ; \mathrm{p}<0.001)$, assuming the Levene's test for the equality of variances (26.28; $p<0.001)$. Analysis of variance of the results of the VDAS scores showed that the main grouping variable (BPD vs. control) explained $41.2 \%$ of the Variance ( $\mathrm{p}<$ 0.01) (Adjusted R Squared =0.37). Gender and the interaction of group and gender failed to show any significant effect.

\section{Dream log data: prospective results}

Each participant had an average score of emotional load, bizarreness, vividness, and effect on daytime mood for his/her reported dreams. These were submitted to independent sample t-test. The self-rated emotional load of dreams differed significantly: more negative dreams were assessed in the BPD group $(\mathrm{t}=-4.02 ; \mathrm{p}<0.001)$. Neither the vividness nor the bizarreness of these specific dreams did differ significantly, but dreams of the BPD patients showed a tendency to have longer effect on waking mood compared to the dreams of the control group $(\mathrm{t}=2.37 ; \mathrm{p}=0.023)($ see Table 1$)$.

\section{Correlations of dream features with daytime behaviour}

Table 2 presents the Pearson's correlation coefficients, depicting the relationship between dream variables and other psychometric measures (Neuroticism, Fantasy, Asser- tiveness) in the whole sample. Neuroticism proved to be a strong and positive correlate of the questionnaire based dream disturbances and a negative correlate of the DE score (the emotional load of the reported dreams; 0 - expressly oppressing, 5 - expressly gratifying), showed a moderate correlation with the DI (the effect on daytime mood of the reported dreams) score and a moderate negative correlation with the neutral-DQQ score. The Fantasy score showed a negative and moderate correlation with dream disturbances and a positive correlation with positive dream emotions. The level of Assertiveness did not correlate with any of the dream variables.

In order to control the effect of age and group membership, and to detect the predictive power of our variables of interest (Neuroticism, Fantasy, Assertiveness) on dream disturbances, we conducted a series of Linear Regression Analyses. First we aimed to determine the predictive power of Neuroticism, Fantasy, Assertiveness on the VDAS score, controlling for age and group membership. At the final step of the analysis only the effect of Neuroticism $(B=0.50 ; t=2.67$; $\mathrm{p}<0.01)$ and Fantasy $(\beta=-0.28 ; \mathrm{t}=-1.99 ; \mathrm{p}$ $<0.05)$ proved to be significant, explaining $45 \%$ of the Variance. We obtained similar results using the emotional load of the reported dreams (DE) as the dependent factor. The effect of group membership lost its level of significance after entering Neuroticism and Fantasy. Furthermore in this analysis Assertiveness showed also a tendency-like correlation (see Table 3).

The Path Analysis determining the possible interaction between Fantasy and Neuroticism showed that Fantasy and Neuroticism are two independent factors predicting the VDAS score (Estimate $=0.004 . ; p=0.901$ ). 
Table 1

Differences between the dream log data of BPD and control subjects: prospective results

\begin{tabular}{lllc} 
Dream characteristics & $\begin{array}{c}\text { BPD }(\mathrm{n}=22) \\
\text { Mean (SD) }\end{array}$ & $\begin{array}{c}\text { Control }(\mathrm{n}=23) \\
\text { Mean (SD) }\end{array}$ & $\begin{array}{c}\text { Test statistic } \\
\text { (t-value, two tailed) }\end{array}$ \\
\hline Emotional load of the reported dreams $^{1}$ & $1.87(0.66)$ & $2.66(0.63)$ & $-4.016^{*}$ \\
\hline Vividness of the reported dreams & $1.25(1.25)$ & $1.36(1.36)$ & -0.885 \\
\hline Bizarreness of the reported dreams $^{*}$ & $1.94(1.95)$ & $2.06(2.06)$ & -0.867 \\
\hline Effect on waking mood of the reported dreams $^{2}$ & $2.47(1.14)$ & $1.68(1.04)$ & $2.366^{* *}$ \\
\hline
\end{tabular}

${ }^{1} 0$ - most negative, 5 - most positive.

21 - uncharacteristic, 5 - even across several days.

$* \mathrm{p}<0.0001 ; * * \mathrm{p}=0.023$

Table 2

Pearson's correlational coefficients showing the relationships between personality measures and dream variables

\begin{tabular}{lcccccc} 
& VDAS & DQQ-negative & DQQ-positive & DQQ- neutral & DE & DI \\
\hline Neuroticism & $0.53^{* *}$ & $0.58^{* *}$ & NS & $-0.38^{*}$ & $-0.50^{* *}$ & $0.49 * *$ \\
\hline Fantasy & $-0.40^{* *}$ & $-0.34 *$ & $0.36^{*}$ & NS & $0.44^{* *}$ & NS \\
\hline Assertiveness & NS & NS & NS & NS & NS & NS \\
\hline
\end{tabular}

VDAS: Van Dream Anxiety Score, DQQ-negative: Dream Quality Questionnaire- negative aspects of dreaming, DQQ-positve: positive aspects of dreaming, DQQ-neutral: neutral aspects of dreaming, DE - emotional load of the reported dreams, DI- the effect on daytime mood of the reported dreams.

* Correlation is significant at the level $\mathrm{p}<0.05$ (two-tailed).

** Correlation is significant at the level $\mathrm{p}<0.01$ (two-tailed).

Table 3

Results of the Linear Regression Analysis. Dependent Factor: Emotional load of the reported dreams (DE). Entered variables in four steps: age and group; Neuroticism; Fantasy; Assertiveness

\begin{tabular}{lclcc} 
Model $(\mathrm{p})$ & Adj. R Square & Variables & Coefficient $\beta$ & $\mathrm{p}$ \\
\hline 1. $(\mathrm{p}=0.001)$ & 0.27 & Age & 0.16 & 0.276 \\
& & Group & 0.59 & 0.000 \\
\hline $2 .(\mathrm{p}=0.001)$ & 0.30 & Age & 0.13 & 0.359 \\
& & Group & 0.42 & 0.020 \\
& & Neuroticism & -0.27 & 0.098 \\
\hline $3 .(\mathrm{p}<0.001)$ & 0.396 & Age & 0.04 & 0.780 \\
& & Group & 0.11 & 0.578 \\
& & Neuroticism & -0.44 & 0.010 \\
& & Fantasy & 0.39 & 0.011 \\
\hline $4 .(\mathrm{p}<0.001)$ & 0.44 & Age & 0.05 & 0.686 \\
& & Group & 0.04 & 0.842 \\
& & Neuroticism & -0.66 & 0.001 \\
& & Fantasy & 0.44 & 0.005 \\
& & Assertiveness & -0.29 & 0.052 \\
\hline
\end{tabular}




\section{The effect of medication on Dream data}

We investigated on an exploratory level the possible effect of SSRI on dream disturbances. Levels of significance for the comparison of mean scores with independent sample t-test between the medicated and the non-medicated BPD subgroups for the VDAS, negative-DQQ and emotional load of the reported dreams were $\mathrm{p}=0.84 ; \mathrm{p}=0.95$ and $\mathrm{p}=0.99$ respectively. However, these results should be interpreted carefully because of the small sample size.

\section{Discussion}

The results of our study indicate that dream disturbances like frequent nightmares, bad dreams, night-terror-like symptoms and dream anxiety are common clinical features of patients diagnosed with BPD. These findings cohere with previous studies reporting a high rate of nightmares and high levels of dream anxiety in $\mathrm{BPD}^{4,5}$. However, these studies used retrospective questionnaires that cannot exclude the possibility of recall biases. In order to diminish the effect of recall biases we examined the emotional quality of a total of 209 dream reports provided by patients with BPD and healthy controls. "Home dream" reports are considered to be a valid tool examining the "dream experience" 21 , and dream reports are not substantially influenced by the reconstructive effects of recall ${ }^{11}$. We found that patients with BPD rated their dreams more distressing, and that their dreams had prolonged effect on waking mood. $68.1 \%$ of the BPD patients reported that they have experienced night terror like symptoms, compared to the $22 \%$ of the control group. This result is worth further investigation, because to our knowledge no previous studies reported association between night terrors and BPD. However, a high frequency of night terrors was shown to be associated with PTSD ${ }^{22}$, while the latter is related in some aspects to BPD or it is often co-morbid with it ${ }^{23}$. Dream disturbances were related to higher levels of Neuroticism. This finding coheres with the report of $\mathrm{Schredl}^{24}$ revealing an association between neuroticism and nightmare frequency in a non-clinical sample. Recently, Levin and Nielsen ${ }^{12}$ traced a comprehensive multilevel model of dream and nightmare formation interpreting the emotional-cognitive level of disturbed dreaming as reflecting the influence of affect load (a consequence of daily variations in emotional pressure) and affect distress (a disposition to experience events with highly reactive emotions) and the neural level of disturbed dreaming as reflecting the dysfunction of the frontolimbic network, comprising the amygdala, the hippocampus, the medial prefrontal cortex, and the anterior cingulate cortex. Our findings fit into the model, since BPD is characterized by unstable relationships (generating affect load) and emotional reactivity (akin to the notion of affect distress), moreover emotional dysfunctions in BPD are linked to anatomical and functional discrepancies in the fronto-limbic network ${ }^{25-28}$.

Assertiveness is considered to be an important coping skill, but it showed only a tendency-like connection with the emotional aspects of dreaming. In contrast, higher levels of Fantasy were inversely related to dream disturbances. These findings indicate that while assertiveness can be key component in appropriate waking functioning, the less controlled cognitive process of dreaming may benefit more from the ability of imagination. Fantasy Proneness, measured by the Creative Experiences Questionnaire 
$(\mathrm{CEQ})^{29}$ was found to be associated with dissociation and deviant nocturnal sleep experiences $^{30}$. This finding is in apparent contrast with our results showing the benign influence of fantasy. Nevertheless, while Fantasy Proneness is characterized by tendencies for absorption and suggestibility the Fantasy scale of the NEO-PIR measures the level of flee-floating imagination and frequent daydreaming. Therefore we consider that CEQ and Fantasy measure two different phenomena, among which only the former is related to dissociation. This is in concordance with the considerations of Giesbrecht and colleagues ${ }^{30}$ emphasizing the difference between Fantasy Proneness and the Openness Factor of the NEO-PIR (the factor where Fantasy scale "belongs").

We suggest that fantasy can be a protective factor against nightmares and bad dreams, and that the free-floating imagination in dreaming can serve the role of emotion regulation by genuinely structuring and rewriting the dream scenario, and thus integrating the negative emotions into more complex cortical networks. One possible function of dreaming is the elaboration of stressful and traumatic events by creating new, adaptive contexts for the negative emotions determining the dreaming process ${ }^{12,31-33}$. Imagery Rehearsal Therapy of Posttraumatic nightmare sufferers is based on the generation of new, alternative outcomes for the "dead end" of the recurrent traumatic nightmares ${ }^{34}$. Our results indicate that therapeutic interventions focusing on the development of imaginative skills may be useful for the treatment of nightmare sufferers.

In sum, our study provides further support for the association between dream disturbances and BPD, links the presence of nightmares, bad dreams and dream anxiety to the severity of emotional instability, and suggests that fantasy is a potential protec- tive factor against dysfunctional dreaming. Furthermore our results suggest that not the BPD diagnosis per se but the specific emotional dysfunctions contribute to the dream disturbances.

Finally, these results need further support, and may be considered as a preliminary study because of the small sample size. Dream collection by laboratory awakenings would be an even more valid method that could rule out the possible effects of selective recall tendencies in dream reports. Additionally, our results are only applicable to women because of the small number of male participants. Despite that we could not detect any effect of the medication on dream quality, the effects of SSRI's in the BPD group cannot be ruled out, because antidepressants may increase dream intensity ${ }^{35}$. However, mainly bizarreness, but not anxiety dreams were enhanced by SSRI's. Moreover, the effect of SSRI on dreaming is still not unequivocal, since another study reports that post-medication dreams of a women suffering from anxiety were more similar to the female population means, than the pre-medication ones ${ }^{36}$.

\section{References}

1. De la Fuente JM, Bobes J, Vizuete C, Mendlewicz J. Sleep-EEG in borderline patients without concomitant major depression: a comparison with major depressives and normal control subjects. Psychiatry Res 2001; 105(12): $87-95$.

2. Battaglia M, Strambi FL, Bertella S, Bajo S, Bellodi L. First-Cycle REM Density in Never-Depressed Subjects with Borderline Personality Disorder. Biol Psychiatry 1999; 45: 1056-1058.

3. Philipsen A, Feige B, Al-Shajlawi A, Schmahl C, Bohus M, Richter H, et al. Increased delta power and discrepancies in objective and subjective measurements in borderline personality disorder. J Psychiatry Res 2005; 39(5): 489-498. 
4. Claridge G, Davis C, Bellhouse M, Kaptein S. Borderline personality, nightmares, and adverse life events in the risk for eating disorders. Pers Individ Diff 1998; 25 : 339-351.

5. Semiz UB, Basoglu C, Ebrinc S, Cetin M. Nightmare disorder, dream anxiety, and subjective sleep quality in patients with borderline personality disorder. Psychiatry Clin Neurosci 2008; 62: 48-55.

6. Giesbrecht T, Merckelbach H. Subjective sleep experiences are related to dissociation. Pers Indiv Diff 2004; 37: 1341-1345.

7. Agargün MY, Savas A, Kara H, Tarhan N, Kincir F, Öz H. Repetitive and nightmares and suicidal behaviour in patients with major depression. Compr Psychiatry 1998; 39(4): 198-202.

8. Agargün MY, Kara H, Özer A, Selvi Y, Kiran Ü, Özer B. Clinical importance of nightmare disorder in patients with dissociative disorders. Psychiatry Clin Neurosci 2003; 57: 575-579.

9. Sjöstrom N, Waem M, Hetta J. Nightmare and Sleep Disturbances in Relation to Suicidality in Suicide Attempters. Sleep 2007; 30(1): 91-95.

10. Giesbrecht T, Smeets T, Leppink J, Jelicic M, Merckelbach H. Acute Dissociation After 1 Night of Sleep Loss. J Abn Psychology 2007; 116(3): 599-606.

11. Cippoli C, Poli D. Story Structure in Verbal Reports of Mental Sleep Experience After Awakening in REM Sleep. Sleep 1992; 15(2): 133-142.

12. Levin R, Nielsen T. Disturbed Dreaming, Posttraumatic Stress Disorder, and Affect Distress: A Review and Neurocognitive Model. Psychol Bull 2007; 133(3): 482-528.

13. Levin R, Young $H$. The relation of waking fantasy to dreaming. Imagination, Cognition and Personality 20012002; 21(3): 201-219.

14. Seligman MEP, Yellen A. What is a dream? Behav Res Therapy 1987; 25: 1-24.

15. Linehan MM. Cognitive-Behavioral Treatment of Borderline Personality Disorder. New York and London: The Guilford Press; 1993.

16. Fogd D, Mangel B, Ujpál Zs, Krekó K, Rózsa S, Unoka Zs. A személyiségzavarok diagnosztikájának megbízhatósága az összehasonlító elemzések tükrében: a SWAP és a SCID-II alkalmazásával szerzett tapasztalatok. (The reliability of the diagnosis of personality disorders: Our experiences with the SWAP and SCID-II - in Hungarian) Psychiat Hung 2004; 19 (Suppl): 41.

17. Teplin D, Raz B, Daiter J, Varrenbut M, Tirrel M. Screening for substance use patterns among patients re- ferred for a variety of sleep complaints. Am J Drug Alcohol Abuse 2006; 32(1): 111-120.

18. Agargün MY, Kara, H, Bilici M, Savas A, Telci M, Semiz B, et al. The Van Dream Anxiety Scale: A Subjective Measure of Dream Anxiety in Nightmare Sufferers. Sleep Hypnosis 1999; 1(4): 204-211.

19. Bódizs R, Simor P, Csóka S, Bérdi M, Kopp MS. Dreaming and health promotion: A theoretical proposal and some epidemiological establishments. European Journal of Mental Health 2008; 3: 35-72.

20. Fruyt F, McCrae R, Szirmák ZS, Nagy J. The FiveFactor Personality Inventory as a Measure of the Five-Factor Model, Belgian, American and Hungarian comparisons with the NEO-PI-R. Assessment 2004; 11(3): 207-215.

21. Domhoff WG. Realistic Simulation And Bizarreness In Dream Content: Past Findings And Suggestions For Future Research. In: Barrett D, McNamara P, eds. The New Science of Dreaming: Content, Recall, and Personality Characteristics, Vol. 2. Westport, CT: Praeger Press; 2007: p. 1-27.

22. Mellman T, David D, Bustamante V, Torres R, Fins A. Dreams in the acute aftermath of trauma and their relationship to PTSD. J Trauma Stress 2001; 14: 241-247.

23. Driessen M, Beblo T, Reddemann L, Rau H, Lange $\mathrm{W}$, Silva A, et al. Is the borderline personality disorder a complex post-traumatic stress disorder? Nerverarznt 2002; 73(9): 820-829.

24. Schredl M. Effects of state and trait factors on nightmare frequency. Eur Arch Psychiatry Clin Neurosci 2003; 253: $241-247$.

25. Rüsch N, van Elst T, Ludaescher P, Wilke M, Huppertz HJ, Thiel T, et al. A voxel-based morphometric MRI study in female patients with borderline personality disorder. Neuroimage 2003; 20: 385-392.

26. Bohus M, Schmahl C, Lieb K. New Developments in the Neurobiology of Borderline Personality Disorder. Curr Psychiatry Rep 2004; 6: 43-50.

27. Herpertz SC, Dietrich TM, Wenning B, Krings T, Erberich SG, Willmes K, et al. Evidence of Abnormal Amygdala Functioning in Borderline Personality Disorder: A Functional MRI Study. Biol Psychiatry 2001; 50: 292-298.

28. Schmahl C, Vermetten E, Elzinga BM, Bremner DA. Positron Emission Tomography Study of memories of Childhood Abuse in Borderline Personality Disorder. Biol Psychiatry. 2007; 55: 759-765.

29. Merckelbach H, Horselenber R, Muris P. The Creative Experiences Questionnaire (CEQ): a brief self-report measure of fantasy proneness. Pers Indiv Diff 2001; 31: 987-995. 
30. Giesbrecht T, Merckelbach H. Dreaming to reduce fantasy - Fantasy proneness, dissociation and subjective sleep experiences. Pers Indiv Diff 2006; 41: 697-706.

31. Hartmann E. Outline for the theory on the nature and functions of dreaming. Dreaming 1996; 6(2): 147-170.

32. Cartwright R, Agargün MY, Kirkby J, Friedman JK. Relation of dreams to waking concerns. Psychiatry Res 2006; 141: 261-270.

33. Nielsen TA, Stenstrom P. What are the memory sources of dreaming? Nature 2005; 437(27): 1286-1289.

34. Krakow B, Hollifield M, Johnston L, Koss M, Schrader R, Warner TD, et al. A controlled study of imagery rehearsal for chronic nightmares in sexual assault survivors with PTSD: a preliminary report. J Traum Stress 2000; 13(4): 589-609.

35. Pace-Schott EF, Gersh T, Silvestri R, Stickgold R, Salzman C, Hobson AJ. SSRI Treatment suppresses dream recall frequency but increases subjective dream intensity in normal subjects. J Sleep Res 2001; 10: 129-142.

36. Kirschner NT. Medication and Dreams: Changes in Dream Content After Drug Treatment. Dreaming 1999; 9(2-3): 195-200.

Address for correspondence: Róbert Bódizs, $\mathrm{PhD}$

Semmelweis University Budapest Institute of Behavioural Sciences

Nagyvárad tér 4

H-1089 Budapest

Hungary

Phone: +36-1-210 2930 / 56404

Fax: +36-1-210 2955

E-mail: bodrob@net.sote.hu 